Publisher homepage: www.universepg.com, ISSN: 2707-4641 (Online) \& 2707-4633 (Print)

https://doi.org/10.34104/ijma.021.0910105

International Journal of Management and Accounting Journal homepage: www.universepg.com/journal/ijma

\title{
Determinates Service Quality and Its Effect on Patients' Satisfaction of Private Medical College Hospitals, Rangpur, Bangladesh
}

\author{
Mst. Shuly Aktar*
}

Department of Marketing, Begum Rokeya University, Rangpur, Bangladesh.

*Correspondence: msa.mkt@brur.ac.bd (Mst. Shuly Aktar, Assistant Professor, Department of Marketing, Begum Rokeya University, Rangpur, Bangladesh).

\begin{abstract}
The current research is both exploratory and descriptive in nature, with a primary focus on SERVQUAL aspects of service quality in private hospitals. The study used a quantitative technique to analyze primary and secondary data, and 255 people were interviewed as part of the sample. Patients' perceptions of the quality of service provided by private hospitals are varied, according to the survey. The perceptions of service recipients are positive in certain areas, such as reliability and responsibility, but negative in others, such as cost and communication. The major parameters impacting the total service quality of private hospitals were identified using regression analysis. In terms of service reliability, the most important factors determining patients' overall service quality are concentration (a composite of 11 measures) and responsiveness (a composite of 9 measures). The study found that the quality of hospital treatments is determined by the incentive system in place at these institutions. Because private hospitals are not funded and rely on revenue from customers, the relevant authorities should be more motivated to deliver high-quality services to patients in order to better satisfy their requirements.
\end{abstract}

Keywords: Service quality, SERVQUAL, Private medical hospital, Satisfaction, and Health care service.

\section{INTRODUCTION:}

One of the Millennium Growth Aims' pinnacle goals is the development of the health sector (MDGs). Bangladesh's administration, like that of all other UN states, has taken the required steps to achieve the MDGs. Following in the footsteps of the government, a variety of local, national, and international NGOs are striving to implement the MDGs and improve people's health. The healthcare business in Bangladesh is essential to the country's long-term socioeconomic development. Health is seen as a highly prized condition (World Health Organization, 2003). Patients' satisfaction is one of the expected outcomes of healthcare, and it is closely connected to healthcare usage. Patient happiness is measured in a variety of ways, including patient UniversePG I www.universepg.com perceptions of healthcare, detecting problems in health-care, and evaluating healthcare (Andaleeb, 2000). The health-care landscape is rapidly shifting across the world (Verma and Sarma, 2000). Patient satisfaction is one of the accepted yardsticks for determining the success of hospital services (Sreenivas and Prasad, 2003). During the Health and Population Sector Program (HPSP) reforms from 1998 to 2003, widespread discontent with government health services did not improve (Andaleeb, 2007). Uneven demand and perceptions of low quality afflict Bangladesh's public health sector. Underutilization of available facilities is a major problem across the nation. The shortage of doctors, nurses, and staff, as well as their unfavorable attitudes and actions, are key barriers to public hospital 
usage. Patients' unfavorable views and unhappiness related to the health care service providers, health care itself, can be shaped by such failures (Dey et al., 2021).

The goal of public hospitals is to offer health service to individuals from all walks of life. However, due to fast population growth and rising health awareness, providing adequate health care to everybody has become impossible. The fact is that public hospitals in Bangladesh are unable to offer patients high-quality health care. In Bangladesh, public hospitals are similarly in supply shortage. Despite the high prices and lengthy processes required in getting visas, collecting foreign exchange, organizing transportation, housing, and identifying night providers of service in Bangladesh, a substantial number of Bangladeshi patients who can afford it are seeking treatment in international institutions. Clearly, the benefits they see exceed the disadvantages. It is for this reason that private hospitals have sprouted up in Bangladesh. This has also opened up the possibility of establishment of private hospitals in Rangpur. Unluckily, worries are present that service quality is also being neglected here. Disregard for conventional treatment methods, a shortage of competent nurses, and needless diagnostic tests are only a few of its major flaws (World Bank, 2003). People who are health-conscious are unhappy with their current treatment and want better health care (Uddin, 2012). Therefore, the residents of the Rangpur metropolitan area have grown. However, the hospitals that are obliged to provide health services to them are grossly inadequate under these conditions.

For a variety of reasons, people from various socioeconomic strata in Bangladesh seek treatment from a range of health providers, including governmental, private, and NGO-based institutions. Economic conditions, health knowledge, socio-demographic factors, and cultural habits may all influence who people choose (Ahmed et al., 2005). It is essential to analyze patient satisfaction in order to evaluate the health care services provided by health care institutes and to quantify patient outcomes. "The patient's perspective is increasingly being recognized as a relevant indication of health care quality, and may, in fact, represent the most important perspective." It's all about perceptions when it comes to customer service. There is no way to test a service before selling it; it can't be stored away, UniversePG I www.universepg.com returned, or swapped (Rust and Zahorik, 1996). For all of these reasons, the most essential factor is the customer's perspective and interpretation of their experience (Gronroos, 2001). Patient satisfaction is a complex construct involving a large number of factors, including the perspective of providers, the physician's knowledge, clinical and communication skills, personal attributes, accessibility, convenience of location and surrounding area, and patients' socio-demographic characteristics, expectations, needs, or desires (Krowinski and Steiber, 1996).

\section{Aim, Objectives and Research question}

This study aims to assess the satisfaction of patients with private medical college hospitals in Rangpur, city of Bangladesh. The aim can be broken into three specific objectives:

Ro 1: To investigate the variables of service quality and patients' satisfaction with private medical college hospitals.

Ro 2: To recognize whether patients' satisfaction is dependent on the five elements of service quality or not.

Ro 3: To identify the degree of patients' satisfaction, focusing on Rangpur's private medical college hospitals.

The aim and objectives can be shaped to form three research questions:

Rq 1: How does the tangibility and reliability of private medical college hospitals contribute to patients' satisfaction?

Rq 2: How do the responsiveness, assurance, and empathy of private medical college hospitals contribute to patients' satisfaction?

Rq 3: How does the cost and communication of private medical college hospitals contribute to patients' satisfaction?

\section{Hypothesis Development}

The following hypotheses can be refined from the research questions. In the present study, the dependent variable is "patient satisfaction". To discover the dependency of this variable, 7 (seven) independent factors were chosen. They are tangibility, reliability, responsiveness, assurance, empathy, communication, and cost of services. Tangibility: Tangibility means representing the service physically. The presence of hos- 
pitals and decoration, hardware, technology, staff and correspondence materials are classified as effects (Hasan et al., 2012). The tangibility of services has a close connection with consumer satisfaction. The above propositions lead to forming the first hypothesis.

H1: There is a clear link between Tangibility and patient satisfaction with private medical college hospital services. Reliability: Reliability is the main determinant of the impression of service quality. Reliability is also known as dependability. Reliability means the ability to carry out the promised service in a conditional and precise manner (Hasan et al., 2012). Service reliability is connected to client satisfaction. The above propositions lead to forming the second hypothesis.

H2: There is a substantial link between hospital service reliability and patient satisfaction.

Responsiveness: Responsiveness means being willing to help. The skill and willingness to assist clients to provide brief assistance is referred to as responsiveness. This measurement emphasizes mindfulness and promptness in dealing with client requests, inquiries, protests, and problems (Hasan et al., 2012). Responsiveness has a close connection with the client satisfaction. The above propositions lead to forming the third hypothesis.

H3: There is a close link between responsiveness and patients' satisfaction with medical services.

Assurance: Assurance of the service always helps to inspire trust and confidence in the minds of consumers. Works' expertise, information, and graciousness, as well as the firm's and its members' ability to transfer confidence and certainty, are all characteristics of affirmation (Hasan et al., 2012). Assurance of the service is highly connected to client satisfaction. The above propositions lead to forming the fourth hypothesis.

H4: There is a clear link between patients' satisfaction with hospital services and assurance.

Empathy: Empathy means treating the client as an individual. Empathy is characterized as the caring, mindful, individualized consideration the bank gives its clients (Hasan et al., 2012). Service Empathy has a connection with client satisfaction. These propositions lead to the fifth hypothesis.

UniversePG I www.universepg.com
H5: There is a beneficial impact between empathy and patient satisfaction with health care services.

Cost: Customer Costs In addition to service aspects, customer costs include not just perceived treatment costs, such as consultation fees, laboratory test fees, travel, medications, and lodging, but also physical costs. Psychic and sensory costs are two types of expenses (Hasan et al., 2012). These propositions lead to the sixth hypothesis.

H6: The higher the level of patient satisfaction in terms of quality, the lower the perceived overall cost of health care services.

Communication: Communication and the process Patient care is facilitated by process characteristics such as updated patient records and uniform patient release processes. Patients' awareness is raised and they are better sensitized to predict results when the nature of the treatment is properly described (Hasan et al., 2012). These propositions lead to the seventh hypothesis.

H7: The patient's perception of the quality of process communication has a favorable impact on perceived service quality.

\section{Rationality of the Study}

The current research is being conducted on Rangpur's private medical college hospitals. Rangpur is a tiny yet developed region in Bangladesh when it comes to socioeconomic importance. In this city, health care is provided by one state medical institution, two private medical colleges, and 104 private hospitals. In Bangladesh, and notably in Rangpur, measuring hospital service quality using existing models is a little-studied topic. The research region of Rangpur city and the current study were performed from the aforementioned vantage point. We believe that the outcomes of this study will aid in the planning and closing of the gap in health care services provided by private medical college hospitals in this city and across the country. This would also help to improve the health-care conditions in Rangpur City, Bangladesh, the profitability of private medical facilities. Finally, the study will aid the public in comprehending the health service facilities and circumstances in this location, as well as enriching the literature on this subject. Due to the scope of this study, we excluded public hospitals, private clinics, and community clinics. 


\section{Review of Literature}

Recent study has also revealed that services or client satisfaction may greatly improve a patient's life quality (Dagger and Sweeney, 2006), allowing service providers to identify particular consumer concerns and solve them (Oja et al., 2006). Other research suggests that unsatisfied health-care customers are more likely to complain to the establishment or seek restitution from it in order to alleviate cognitive dissonance and poor consumption experiences (Nyer, 1999). Furthermore, dissatisfaction has serious consequences: patients are less likely to adhere to treatment regimens, are more likely to miss follow-up appointments. However, while the Bangladesh government has begun toadd the health sector into its poverty reduction plan, the public health system is beset by unequal demand and low-quality perceptions (Andaleeb et al., 2007). According to one study, the overall usage rate of public health services is as low as $30 \%$ (Ricardo et al., 2004). Another study found that between 1999 and 2003, the rate of usage of public health care services was dropping, (CIET, 2003). The study identified the absenceof doctors and nurses, their negative behaviors, including the lack of medicines, long distance travel and waiting times, as the major factors of dissatisfaction and barriers to use of public hospital services. Information, billing, food services, and staff all impact the healthcare system service quality in hospitals, according to Sower et al. (2001). Consumers were strongly thoughtful to the price of healthcare services at hospitals, according to Sahn et al. (2002), and this response was stronger for those with lower incomes. Sohail (2003) looked at non-clinical components of service quality in Malaysian hospitals. SERVQUAL was used to determine patients' expectations and perceptions of service quality. The findings, which were based on the mean differences between expectations and perception, show that, as a result of Malaysian hospitals' modernization and accreditation, patients' perceived value of treatments exceeds expectations for all of the variables studied. The World Health Organization, (2003) proposed ways to improve healthcare service quality. Increasing funding, hospital equipment facilities, strengthening management, creating standards, and giving training to health care providers are among the approaches. Patients' satisfaction with tangibility and assurance services in South AfriUniversePG I www.universepg.com can public hospitals was assessed by Jager and Plooy, (2007). The hygiene of the facilities and the overall performance of the equipment were discovered to be the most relevant tangibility factors. The most significant assurance factors have been assessed to be employee politeness and personal safety. Figen and Ebru, (2010) evaluated the service quality of Northern Cyprus' public as well as private hospitals, considering the service quality characteristics that effect patient satisfaction. The primary determinants of service quality in those hospitals were found to be reliability, confidence, empathy, and tangibility. In all three service quality measures, private hospitals showed lower disparities than public hospitals, according to the research. According to Manimaran et al. (2010), there is a discrepancy between patients' expectations and perceptions of service quality. They proposed that, so as to close the gap, hospitals should enhance service quality by concentrating on tangibility, assurance, empathy, responsiveness, and dependability aspects. The service quality gap between patient perceptions and expectations was assessed by (Ahmed and Samreen, 2011). It was discovered that there was a significant disparity in characteristics such as the availability of informational pamphlets, waiting times, error-free records, and service fees. Solayappan et al. (2011) investigated service quality disparities at Chennai's top hospitals. They discovered that the dependability and assurance aspects had a significant disparity. The lack of interest of hospital employees in resolving the situation, communication about services, differences between promised and provided treatments, and lack of personal attention were all factors that negatively impacted patient satisfaction. Patients using public hospitals, according to Irfan et al. (2012), believe that public hospitals are not making apparent efforts to provide higher quality services to patients. It was proposed that public hospitals should place a greater emphasis on this aspect of service quality. Ramez (2012) evaluated the service quality of Bahraini healthcare professionals. $\mathrm{He}$ discovered that the empathy, concrete, and responsiveness characteristics had the most impact on hospital service quality. In Jordan's public and private hospitals, Zamil et al. (2012) studied the influence factors of service quality on patient satisfaction. For determining customer satisfaction with service quality in both the public and commercial sectors, the 'SER- 
VPERF' method was used to assess service quality in five Indian hospitals. The quality of service in private hospitals was determined to be superior to that in public hospitals. However, out of all the service quality dimensions in the public and private sectors, the responsiveness component of health service quality has the lowest mean. Instead of buying more technology, Jin et al. (2013) proposed that, in order to increase patient happiness in hospitals, more money should be spent on educating the medical staff's professional competence, communication skills, and problemsolving abilities.

Johnson (2013) looked into many aspects of service quality in Thailand hospitals. The most influential factor was responsiveness, which was followed by empathy, tangibles, certainty, and, lastly, reliability. To retain clients, Rahman and Kutubi, (2013) advised that hospitals in Dhaka concentrate on communication, responsiveness, and empathy aspects. Mashhadiabdol et al. (2014) investigated the quality of service in Iranian hospitals and discovered a large difference between patients' and staff opinions. Sharmila and Krishnan, (2014) studied service quality in Chennai hospitals and discovered that tangibility had a higher influence on service quality than cost. Andaleeb, (2000) conducted study compares the quality of services provided by public and private hospitals in Bangladesh. Data analysis techniques were used to check for data entry errors and obtain descriptive statistics. Results suggest that poor patient perceptions are driving many patients to private hospitals. Hussain, (2016) seeks to investigate Bangladeshi patients' experiences with public health care services, as well as their self-perceptions of health and their expectations and demands of government health practitioners and service providers. To obtain the relevant information, the study used a qualitative research approach using different data collection procedures such as interviews, focus group discussions (FGDs), documentation surveys, and so on.

Mahejabin, (2016) evaluated patient satisfaction with services given in a rural Bangladesh primary health care center. The study participants were chosen using a simple non-probability selection method. A face-toface interview was performed using a semi-structured, pre-tested questionnaire. According to the findings of

UniversePG I www.universepg.com this survey, the majority of patients thought the hospital's general basic amenities, such as lights, signboards, cafeteria services, and bathroom facilities, were acceptable. Patients' views of excellent health care are explained by Uddin, (2016). The purpose of this study is to determine patient satisfaction with doctors' services in a Bangladeshi government hospital. The principal component analysis reveals that the initial solution includes a single factor with Eigen values larger than 1. It was responsible for about $61 \%$ of the variance in the original variables. Zubayer, (2017) mentioned that the healthcare service quality depends on some factors as knowledgeable doctor \& hygienic nurses, language and cleanliness, degrees \& equipment, tests and meals, needs and caring, attracttive $\&$ punctual, examination and skills, doctor and nurses in a private hospital. These factors influence patient choice intension and satisfaction. Ahmed et al. (2017) revealed that private hospitals charge more than public hospital but private hospitals ensuring more quality service than that of public medicals through improved medical system, skilled staff and welldesigned service standards. Because of better medical facilities customers are satisfied and loyal to the private hospital. Kalam, (2020) found that lack of proper staff training, monitoring and supervision, drug and supplies poor information provision, long waiting time, poor cleanliness, lack of privacy, and inadequate visiting hours are causes for dissatisfaction of patient. Patient satisfaction is a big issue for private hospital. $\mathrm{He}$ also found that most of the patients come to Tairunnessa Memorial Medical College and HospitalGazipur from urban areas and above 50\% patients are satisfied with various healthcare services. Begum et al. (2021) discussed that taking medical services in Bangladesh from private medical is much higher costly and satisfying than public medical centers. Treatment outcome in private medical has better success rate. Most of the private hospital located in urban areas that are why people of urban areas choose to go to private hospitals. The majority of research studies on service quality were found to be from other cities and countries, but the current study attempts to fill the gap in the literature by evaluating the validity of five SERVQUAL dimensions in Rangpur private hospitals and identifying the important relevant dimensions in this context. 


\section{Research Gap}

Concerns regarding the quality of health-care services in Bangladesh have led to a loss of faith in both public and private hospitals, as well as a decrease in the usage of public health facilities and an increase in Bangladeshi patients seeking treatment in neighboring countries. In these circumstances, assessing the quality of the country's health-care services has become important, and patients' voices must begin to play a bigger role. The findings of the literature demonstrate that customer satisfaction, repurchase behavior, and recommendation behavior are all influenced by an organization's perceived service quality. People in our nation receive many types of health care services from private medical hospitals. However, little is known about the current service quality of private medical hospitals based on credible research. The present facilities are insufficient, and how these facilities provide for patients' needs is overlooked. Many studies have been conducted on service quality measurement, service satisfaction, the health care situation in Bangladesh, and patient satisfaction with health care services and factors of hospital choice, according to various literature. In Bangladesh, and notably in Rangpur, measuring hospital service quality using existing models is a little-studied topic. To our knowledge, no comprehensive research has been done to assess the service quality of private medical college hospitals in Bangladesh, particularly in Rangpur. This is a research issue with a distinct gap. The current research is a good start to fulfilling this gap. A greater knowledge of the service quality provided by private medical facilities could aid policymakers and decision-makers in adopting and implementing effective strategies to enhance health care in the country.

\section{Conceptual Development}

The theoretical framework is mainly based on the literature review. According to previous work, the constructs are integrated into a theoretical framework. The framework guides the development of research hypotheses, which examine the interrelationships among research constructs.

The SERVQUAL model, established by Parasuraman et al. is one of the most widely used service quality measuring models (1985, 1986, 1988, 1991, 1993, 1994; Zeithaml et al., 1990). Parasuraman et al. $(1985,1988)$ created the SERVQUAL scale to provide a general tool for assessing service quality across a wide variety of service areas. Evaluation of quality for services is more challenging than assessing quality for things due to their intrinsic diversity, inseparability of production and consumption, perishability, and intangibility (Frochot and Hughes, 2000). Service quality is difficult to describe and evaluate because of these unique features. In 1985, Parasuraman et al. (1985) established the SERVQUAL scale, which has proven to be one of the most popular and lasting among academics and practitioners alike. SERVQUAL (Parasuraman et al., 1988) is a commonly utilized research tool in a variety of service sectors (Buttle, 1996; Carman, 1990). Tangibles, responsiveness, assurance, empathy, and dependability are five factors that impact customer perceptions of service quality, according to Parasuraman et al. (1985).

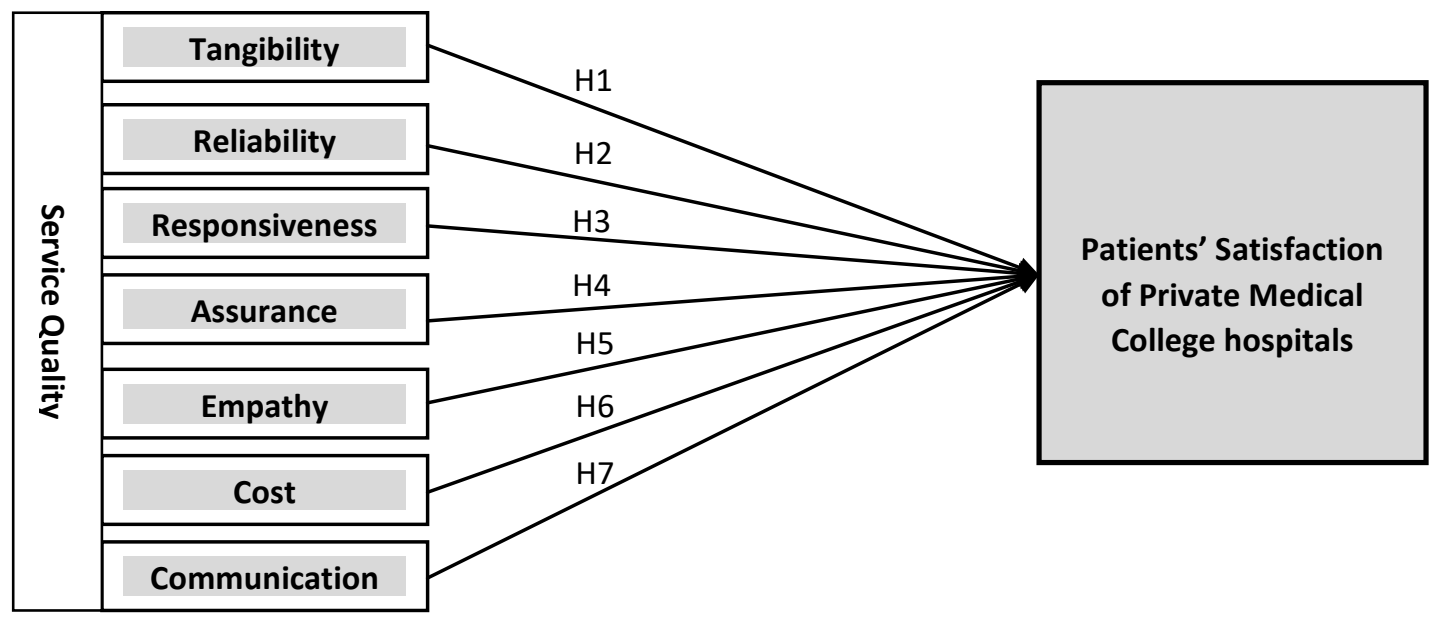

Fig 1: A Theoretical Approach to Measuring Hospital Service Quality. 


\section{MATERIALS AND METHODS:}

Research approach - The current research is both exploratory and descriptive in character.

Sampling technique - The study's population consisted of persons who were inpatients at private medical college hospitals in Rangpur City. Because they have substantial and contemporary medical facilities, these private medical college hospitals represent complete health care services in the private sector in this region. A sample size of 255 patients was chosen from this list using simple random selection.

Questionnaire design - On the basis of previous research and insights from in-depth qualitative interviews, a preliminary version of the questionnaire was produced in English. The measurements were then translated into Bangla and retranslated until a panel of experts, proficient in both English and Bangla, concluded that the two versions were sufficiently similar. In a systematic style, scale items were assessed on five-point Likert scales (Likert, 1932). Each component was anchored at 1 with the verbal remark "very poor" and 5 with the verbal statement "very excellent." For health-care surveys, this format has been proposed (Elbeck 1987; Steiber 1989). To establish adequate measurement characteristics (reliability and validity) of the identified constructs, several items were employed. The questionnaire was pre-testing several times to confirm that the wording, structure, length, question sequencing, and scale range (5-point vs. 7-point) were all suitable. Feedback was gathered from around 15 hospital users at each pre-test. This type of input was crucial in improving the measure's quality.

Data collection method - This study employed a quantitative research design to look at the link between research components, and the technique of inquiry was a survey. The data was obtained from patients who have visited the private medical college hospitals at least once. The survey was conducted during December, 2020 in the areas of Rangpur. The following are the criteria that looked into: tangibles, dependability, responsiveness, assurance, empathy, communication, and cost; total service quality. This study's hypotheses were developed using the framework, and they were designed to see if the correlations between variables in the framework were supported or not. The objectives were met using both primary and secondary data. To collect primary data, a structured questionnaire was created. Secondary data has been gathered from a variety of sources.

Data analysis - Data was analyzed using a variety of statistical methods, including descriptive statistics, ANOVA, and principal component analysis. To ensure the questionnaire's reliability, Cronbach's alpha was calculated for each component. Correlation (Pearson product-moment correlation) and multiple regression models were employed to explore the link between service quality factors and patients' satisfaction. To analyses and demonstrate the data, statistical tools and techniques from SPSS 22 version were used here.

\section{RESULTS AND DISCUSSION:}

The study deals with the measurement of the degree of satisfaction patients with private medical college hospitals in Rangpur based on several dimensions, including Reliability, Assurance, Tangibility, Empathy, and Responsiveness, other clients' satisfaction dimensions. Findings of the study based on the data collections are -

Table1: Demographic Profile of the respondents.

\begin{tabular}{|c|c|c|c|}
\hline \multicolumn{2}{|c|}{} & Frequency & Percent \\
\hline \multirow{2}{*}{ Gender } & Male & 148 & 58.04 \\
\cline { 2 - 4 } & Female & 107 & 41.96 \\
\hline \multirow{2}{*}{ Age (in years) } & Below 20 years & 17 & 6.66 \\
\cline { 2 - 4 } & $20-30$ years & 25 & 9.80 \\
\cline { 2 - 4 } & $30-40$ years & 40 & 15.68 \\
\cline { 2 - 4 } & $41-50$ years & 59 & 23.13 \\
\cline { 2 - 4 } & $50+$ & 114 & 44.70 \\
\hline
\end{tabular}




\begin{tabular}{|c|c|c|c|}
\hline Educational Qualification & Below SSC & 16 & 6.27 \\
\cline { 2 - 4 } & SSC & 29 & 11.37 \\
\cline { 2 - 4 } & HSC & 67 & 26.27 \\
\cline { 2 - 4 } & Graduate & 79 & 30.98 \\
\cline { 2 - 4 } & Post Graduate & 64 & 25.09 \\
\hline Profession of the respondent & Student & 36 & 14.11 \\
\cline { 2 - 4 } & Service holder & 60 & 23.52 \\
\cline { 2 - 4 } & Business & 60 & 23.52 \\
\cline { 2 - 4 } & Retired person & 99 & 38.82 \\
\hline Family Monthly Income & Below TK 11,000 & 30 & 23.76 \\
\cline { 2 - 4 } & Between TK 11,000 to 31,000 & 60 & 31.37 \\
\cline { 2 - 4 } & Between TK31,001 to 50,000 & 80 & 11.76 \\
\cline { 2 - 4 } & Between 50,001 to 70,000 & 30 & 11.76 \\
\cline { 2 - 4 } & Between TK 70,001 to 100000 & 30 & 9.80 \\
\cline { 2 - 4 } & Above TK 100001 & 25 & 23.52 \\
\hline
\end{tabular}

Table 2: Shows the opinion given to the attributes by the patients.

\begin{tabular}{|c|c|c|c|c|c|}
\hline \multirow{2}{*}{\multicolumn{2}{|c|}{$\frac{\text { S. N. }}{1 .}$}} & Service Dimensions/Attributes & \multirow[t]{2}{*}{$\mathbf{N}$} & \multicolumn{2}{|c|}{ Result } \\
\hline & & Tangibility: [ Grand Mean 3.8657] & & \multirow{2}{*}{$\frac{\text { Mean }}{4.37}$} & \multirow{2}{*}{$\begin{array}{l}\text { SD } \\
.680\end{array}$} \\
\hline Tan & a) & The cabin, ward, mattresses, and flooring are all spotless. & 255 & & \\
\hline Tan & b) & The hospital appears to be extremely appealing. & 255 & 4.15 & .530 \\
\hline Tan & c) & Doctors have a squeaky-clean look. & 255 & 3.87 & .650 \\
\hline Tan & d) & Nurses have a neat and tidy look. & 255 & 3.80 & .632 \\
\hline Tan & e) & The grounds and surrounding areas of the hospital are well-kept and tidy. & 255 & 3.90 & .737 \\
\hline Tan & f) & The look of the other employees is clean. & 255 & 3.67 & 1.030 \\
\hline Tan & g) & The toilets and facilities are in good condition. & 255 & 3.30 & .720 \\
\hline \multicolumn{2}{|c|}{2.} & Reliability: [Grand Mean 3.498] & & & \\
\hline Rel & a) & The number of doctors in hospitals was sufficient. & 255 & 3.80 & 1.162 \\
\hline Rel & b) & Doctors are highly trained and experienced professionals. & 255 & 3.55 & 1.123 \\
\hline Rel & c) & Patient records are meticulously kept. & 255 & 3.65 & .855 \\
\hline Rel & d) & The therapy was monitored by doctors on a regular basis. & 255 & 3.65 & 1.105 \\
\hline Rel & e) & The results of all tests are accurate and dependable. & 255 & 3.63 & .665 \\
\hline Rel & f) & Nurses were plentiful in hospitals. & 255 & 3.55 & 1.122 \\
\hline Rel & g) & Nurses are really concerned. & 255 & 3.61 & 1.020 \\
\hline Rel & h) & Nurses have extensive training and experience. & 255 & 3.19 & 1.023 \\
\hline Rel & i) & Machines and lab equipment have been updated to a great degree. & 255 & 3.59 & 1.190 \\
\hline Rel & j) & Staffs and assistance are efficient & 255 & 3.08 & 1.235 \\
\hline Rel & k) & All service providers are trained & 255 & 3.18 & 1.036 \\
\hline \multicolumn{2}{|c|}{3.} & Responsiveness: [Grand Mean 3.446] & & & \\
\hline Res & a) & Doctors are concerned about their patients. & 255 & 3.56 & .890 \\
\hline Res & b) & The doctor paid close attention to you. & 255 & 3.51 & 1.005 \\
\hline Res & c) & Nurses take care of patients in a timely manner. & 255 & 3.59 & 1.123 \\
\hline Res & d) & Doctors were always willing to help you when you needed it. & 255 & 3.51 & 1.151 \\
\hline Res & e) & Doctors are eager to address any questions you may have. & 255 & 3.45 & 1.101 \\
\hline Res & f) & When you needed it, the nurses were there for you. & 255 & 3.21 & 1.071 \\
\hline Res & g) & Staffs and attendance are very cooperative & 255 & 3.35 & 1.250 \\
\hline Res & h) & Staffs and attendance are corticoids & 255 & 3.39 & 1.113 \\
\hline \multicolumn{2}{|c|}{4} & Assurance: [ Grand Mean 3.444] & & & \\
\hline Ass & a) & Doctors provide patients with clear prescription recommendations. & 255 & 3.60 & .861 \\
\hline
\end{tabular}




\begin{tabular}{|c|c|c|c|c|c|}
\hline Ass & b) & Doctors offered reasonable responses to your condition's queries. & 255 & 3.42 & 1.021 \\
\hline Ass & c) & In the hands of the physicians, you felt completely secure. & 255 & 3.50 & 1.123 \\
\hline Ass & d) & The findings of the tests were conveyed to you by the doctors. & 255 & 3.40 & 1.022 \\
\hline Ass & e) & Your prior condition was adequately discussed by the doctor. & 255 & 3.30 & 1.123 \\
\hline \multicolumn{2}{|c|}{5.} & \multicolumn{4}{|l|}{ Empathy: [ Grand Mean 3.39] } \\
\hline Emp & a) & $\begin{array}{c}\text { The hospital guarantees proper treatment, care, and prevention of } \\
\text { negative outcomes. }\end{array}$ & 255 & 3.43 & 1.126 \\
\hline Emp & b) & Nurses are ready to help when it's required. & 255 & 3.55 & .99821 \\
\hline Emp & c) & $\begin{array}{l}\text { Nurses are aware of the need of infection control and cleanliness for } \\
\text { patients. }\end{array}$ & 255 & 3.45 & 1.0588 \\
\hline Emp & d) & $\begin{array}{l}\text { Patients' requirements for sleep, rest, and tranquility are met at the } \\
\text { hospital. }\end{array}$ & 255 & 3.29 & 1.0310 \\
\hline Emp & e) & $\begin{array}{l}\text { The hospital provides advice on how to improve one's health and make } \\
\text { the most use of health-care resources. }\end{array}$ & 255 & 3.33 & 1.0440 \\
\hline Emp & f) & Patients are given personalized care by nurses. & 255 & 3.29 & 1.1211 \\
\hline \multicolumn{2}{|c|}{6.} & \multicolumn{4}{|l|}{ Process and communication: [Grand Mean 2.6066] } \\
\hline Com & a) & Customers' complaints are handled courteously by the hospital. & 255 & 3.50 & .99281 \\
\hline Com & b) & The hospital will give you with all of the information you want. & 255 & 2.96 & 1.3712 \\
\hline Com & c) & Personal belongings are kept safe in the hospital. & 255 & 2.70 & 1.1213 \\
\hline Com & d) & Greetings and entertainment are provided by the hospital. & 255 & 2.30 & 1.1412 \\
\hline Com & e) & The hospital accepts payments through cheque and online. & 255 & 2.23 & 1.3121 \\
\hline Com & f) & The hospital sends out billing statements on a regular basis. & 255 & 1.95 & 1.0098 \\
\hline \multicolumn{2}{|c|}{7.} & Cost: [ Grand Mean 3.074] & & & \\
\hline Cos & a) & The cost of a doctor's consultation is affordable. & 255 & 3.20 & 1.0861 \\
\hline Cos & b) & The cost of a lab test is fair. & 255 & 3.25 & 1.1651 \\
\hline Cos & c) & The price of an ambulance service. & 255 & 3.02 & 1.3131 \\
\hline Cos & d) & The cost of renting a cabin or a bed is inexpensive. & 255 & 3.10 & 1.2131 \\
\hline Cos & e) & The price of a drug is reasonable. & 255 & 2.80 & 1.1121 \\
\hline
\end{tabular}

Table 3: Service quality perception toward the hospital services $(\mathrm{N}=255)$.

\begin{tabular}{|c|c|c|c|}
\hline Variable & Frequency & Percent & Cumulative percent \\
\hline Excellent & 30 & 11.76 & 11.76 \\
\hline Good & 70 & 27.45 & 76.21 \\
\hline Average & 95 & 37.25 & 94.1 \\
\hline Bad & 45 & 17.64 & 100 \\
\hline worst & 15 & 5.89 & \\
\hline Total & 255 & & \\
\hline
\end{tabular}

Note: The average level of service quality goes from 1 (worst) to 5 (Excellent)

Assessing patients' service quality perceptions of Private Medical College Hospitals: Patients were asked to rate the quality of different hospital services on a five-point Likert scale ranging from one to five, with one being extremely poor and five being very excellent. The results are listed in Table 2. Intangibility $(M=3.8657)$ had the highest mean score among the many service dimensions, followed by Responsiveness $(\mathrm{M}=3.446)$ and Reliability $(\mathrm{M}=3.498)$, while Service cost $(\mathrm{M}=3.074)$ and procedure and communication $(\mathrm{M}=2.6066)$ had the lowest mean scores. AttriUniversePG I www.universepg.com butes mean scores below 2.75 are considered bad; scores between 2.75 and 3.25 are considered ordinary; scores 3.25 to 4.00 are considered good; and scores over 4.00 are considered outstanding.

\section{Overall Patients' Perceptions towards the Private} Medical College Hospitals - Respondents were also asked about their views on several service aspects in private hospitals. Table 2 shows a summary of the findings. According to the results of the survey, 11. $76 \%$ of respondents stated the overall service quality is outstanding, 27.45 percent said well, and 37.25 percent 
said ordinary. It was also discovered that $17.64 \%$ of respondents rated the total service quality as bad, while 5.89 percent rated it as worse. The mean overall perceived service quality level of respondents is 3.332 , indicating that consumer perceptions of overall service quality are average on a 5-point scale.

Result of Factor Analysis - After analyzing patients' perceptions of various services, the authors attempted to categorize them using Factor Analysis in SPSS 22. The first answer was created using the main components factor technique. The correlation matrix has an overall significance of 0.000 , with a Bartlett test of sphericity value of 1796.126 and 378 degrees of freedom. The statistical probability and test revealed a strong connection between the variables, indicating that factor analysis was necessary. The total KaiserMeyer-Olkin index of sample adequacy was 0.758 , which was commendable (Hair et al., 1999).The statis- tical probability and test revealed a strong connection between the variables, indicating that factor analysis was necessary. Table 4 shows factor analysis result. The findings of the factor analysis are shown in Table 4. Before the rotation, the Eigen values showed that the seven-factor solution explained 76.805 percent of the overall variation. Each variable's communality ranged from 0.415 to 0.857 . The Cronbach's alpha was calculated for each component to assess its dependability and internal consistency. The alpha coefficients for the seven variables varied from 0.5697 to 0.8185 , according to the findings. Because 0.50 is the minimal number for approving the reliability test, the findings were deemed more than dependable (Nunnally, 1967)

Correlation Analysis - A correlation coefficient was used in the study to determine the strength of a linear relationship between the respondents' overall impression of service quality and seven criteria.

Table 4: Shows factor analysis result.

\begin{tabular}{|c|c|c|c|c|c|c|}
\hline \multirow{2}{*}{ Components } & \multicolumn{3}{|c|}{ Extraction Sums of Squared Loadings } & \multicolumn{3}{c|}{ Rotation Sums of Squared Loadings } \\
\cline { 2 - 7 } & Total & \% of Variance & Cumulative \% & Total & \% of Variance & Cumulative \% \\
\hline 1 & 16.134 & 34.587 & 34.587 & 11.699 & 21.201 & 21.291 \\
\hline 2 & 7.701 & 12.800 & 47.387 & 10.117 & 18.036 & 39.237 \\
\hline 3 & 5.836 & 8.100 & 55.487 & 5.196 & 10.142 & 49.379 \\
\hline 4 & 3.827 & 7.008 & 62.495 & 4.137 & 9.202 & 58.581 \\
\hline 5 & 3.246 & 5.070 & 67.565 & 3.168 & 8.624 & 67.205 \\
\hline 6 & 2.077 & 5.123 & 72.688 & 2.134 & 4.411 & 71.616 \\
\hline 7 & 1.880 & 4.117 & 76.805 & $2 . .114$ & 5.189 & 76.805 \\
\hline
\end{tabular}

Table 5: Correlation between Overall Service Quality and Factors.

\begin{tabular}{|c|c|c|c|}
\hline Overall Service Quality & $\mathbf{N}$ & Pearson Correlation & Sig.(2-tailed) \\
\hline Factor 1: Tangibility & 255 & $.270^{* *}$ & .000 \\
\hline Factor 2: Reliability & 255 & $.419^{* *}$ & .000 \\
\hline Factor 3: Responsiveness & 255 & $.360^{* *}$ & .000 \\
\hline Factor 4: Assurance & 255 & $.255^{* *}$ & .000 \\
\hline Factor 5: Empathy & 255 & .249 & .058 \\
\hline Factor 6:Process and communication & 255 & .219 & .069 \\
\hline Factor 7: Service cost & 255 & $.229^{* *}$ & \\
\hline
\end{tabular}

** At the 0.01 level, the correlation is significant (2-tailed)

The connection between overall quality level and seven variables is positive and significant at the 0.01 level, as shown in Table 5. As a result, the study finds that there is a stronger link between total ser-vice quality and Reliability, Responsiveness, Assurance, and Service Cost than with Tangibility, Process and Communication, and Empathy. These findings backed up premise 1 to 7 , indicating that there is a strong link between total service quality and tangibility, dependability, responsiveness, assurance, and service cost. $\mathrm{H} 1, \mathrm{H} 2, \mathrm{H} 3, \mathrm{H} 4$, and $\mathrm{H} 7$ were approved, but, H5, and H6 were denied. 
Analysis of Multiple Regressions - The current study employed regression analysis to evaluate and explain the casual association between variables in order to further provide support for hypothesis 1 . The multiple linear regression technique was used because it offered the most accurate interpretation of the independent variables and allowed researchers to determine if the discovered independent factors had a substantial impact on overall service quality. The standardized factor scores were used to express the seven independent variables. Based on the beta coefficients, the important variables that remained in the regression equation were ranked in order of importance. The dependent variable, patients' total service quality assessment, was assessed using a 5-point Likert-type scale as a proxy indication of patients' perceptions of hospital services. The following specification was used to define the equation for patients' total service quality perception: The regression analysis results were shown in Table 7. The multiple correlation coefficients $(\mathrm{R})$, coefficient of determination (R2), and $F$ ratio are used to determine the regression model's goodness-of-fit. The $\mathrm{R}$ of the independent variables (seven components, $\mathrm{X} 1$ to $\mathrm{X} 7$ ) and the dependent variable (patients' overall service quality perception) is 0.450 , indicating that the patients' over-all service quality and the seven aspects of service quality showed positive and moderate relationships. The R2 is 0.233 , implying that the seven parameters can explain more than $23 \%$ of the variation in total service quality. The $\mathrm{F}$ ratio of 6.72 indicates whether the regression model's results might have happened by chance. The $\mathrm{p}$ value is 0.000 , which indicates that the result is extremely significant. The regression model predicted the variance of patients' total service quality in respect to the seven variables with a goodness-of-fit of around 23\%, as evaluated by the R, $\mathrm{R} 2$, and $\mathrm{F}$ ratios described earlier.
In other words, at least one of the seven variables is critical in determining the total quality of service provided by private hospitals in Rangpur to patients. Regression (Table 6) based on the dimensions, the results of the patients' total service quality level (N-255).

\section{Model Summary}

\begin{tabular}{|c|c|c|c|}
\hline $\mathbf{R}$ & $\mathbf{R}^{2}$ & Adjusted $\mathbf{R}^{\mathbf{2}}$ & Std.Error of the Estimate \\
\hline .450 & .233 & .180 & .685 \\
\hline
\end{tabular}

Dependent variable: Overall service quality, independent variables: seven factors. The beta coefficients may be utilized in regression analysis to explain the relative relevance of each of the seven aspects (independent variables) in contributing to the variation in the overall service quality level of patients (dependent variable). When it comes to the relative relevance of the seven characteristics, Factor 2 (Reliability: beta=$0.277, \mathrm{p}=0.001$ ) contributes the most and has the most weight for patients' overall service quality, followed by Factor 3 (Responsiveness: beta $=0.231, \mathrm{p}=0.003$ ). These two elements have a strong link with the total degree of service quality. If all other factors were maintained constant, a one-unit improvement in service quality with the responsiveness factor would result in a 0.277unit gain in total service quality with private hospital services. To summarize, not all underlying qualities are equally important. As a result, the findings of multiple regression analysis rule out hypotheses 2 and 3, which claim that there is a link between these dimensions and total service quality.

Analysis of Variance

\begin{tabular}{|c|c|c|c|c|c|}
\hline & $\begin{array}{c}\text { Sum of } \\
\text { Squares }\end{array}$ & df & $\begin{array}{c}\text { Mean } \\
\text { Squares }\end{array}$ & F & Sig.(p) \\
\hline Regression & 24.350 & 7 & 3.173 & 6.691 & .000 \\
\hline Residual & 93.127 & 198 & .464 & & \\
\hline Total & 117.567 & 205 & & & \\
\hline
\end{tabular}

\section{Result of Regression Analysis}

\begin{tabular}{|c|c|c|c|c|c|}
\hline Independent variable & B & Std. Error & Beta & T & Sig. \\
\hline (Constant) & 2.114 & .384 & & 5.519 & .000 \\
\hline Tangibility & 0.066 & .092 & .057 & 0.720 & .000 \\
\hline Reliability & 0.288 & .089 & .277 & 3.053 & .001 \\
\hline Responsiveness & 0.337 & .079 & .231 & 2.959 & .003 \\
\hline Assurance & 0.068 & .069 & .059 & 0.743 & .458 \\
\hline Empathy & 0.060 & .065 & .051 & 0.673 & .501 \\
\hline Process and communication & 0.011 & .100 & .007 & 0.114 & .808 \\
\hline Service cost & 0.151 & -.057 & -.155 & -1.700 & .070 \\
\hline
\end{tabular}

*Represents $\mathrm{p}<0.05$ 


\section{RECOMMENDATIONS:}

The study's findings describe how patients view the service quality of private medical college hospitals in Rangpur, Bangladesh. This study has numerous theoretical implications that may be added to the expanding body of literature on service quality in Bangladesh, particularly in health care services. In terms of the service quality of private medical college hospitals in the research region, Table 2 shows that the tangible and reliability aspects were scored highly among all SERVQUAL dimensions. The grand mean values for these two dimensions are 3.865 and 3.498, respecttively. The average mean value for responsiveness, assurance, and empathy was 3.446, 3.444, and 3.39, respectively. Process, communication, and cost, on the other hand, received lower scores than the other categories. In private hospitals, treatment costs are also thought to be excessive, which may be due to the diverse clientele served and their varying socioeconomic levels. Those that choose private hospitals are often from the higher income brackets and are in a much better financial position. Even so, they may not all be using the finest hospitals, which contributes to the illusion of low treatment costs. The study's findings indicated that, even if just four of the seven criteria were included, F2 was the most important (reliability), F3 (responsiveness), F4 (assurance), and F7 (cost) all have a role in total service quality. This conclusion may be beneficial to private hospital policymakers in developing measures to preserve or improve service quality and competitiveness. In other words, F2 (reliability) and F3 (responsiveness) are more contributing elements to improving total service quality (Table 6). As a result, service firms should provide quality service with dependability, such as doctors following up on patients on a regular basis, an adequate number of doctors and nurses, well-maintained patient records, accurate and reliable test results, and doctors who are qualified and experienced, caring nurses, well-trained and experienced nurses, and modernized machines and equipment. In addition, those involved in the development of the service must contribute more in terms of their createvity to offer a variety of unique services that can ensure a high level of customer satisfaction, such as nurses attending sincerely when needed, nurses looking after them in a timely manner and doctor's listenUniversePG I www.universepg.com ing attentively and willing to answer any questions. It's also worth mentioning that in Bangladesh, healthcare providers are sometimes more concerned with the cost of service than with its quality (Mezgebe, 2020). People in Bangladesh, they say, are hesitant to pay more for better service.

According to this study, cost is not a significant factor in patient satisfaction, particularly in the private sector and for those who utilize international institutions; rather, treatment quality is considerably more important. As a result, policymakers must understand that a segment of the population chooses high-quality services over a less expensive but inferior option that might increase future expenses. It could be beneficial to look at health-care delivery from the perspective of market segments, where prices are prioritized for some and services are prioritized for others, but with a proper balance that satisfies basic requirements.

\section{CONCLUSION:}

Concerns about the quality of health-care services in Bangladesh have caused people to lose trust in government institutions. As a result, evaluating the country's private medical facilities has become critical, with the patient's voice playing an increasingly important role. Private medical hospitals are becoming more common. As a result, we must pay greater attention to improving the service quality of private medical facilities, and the government must oversee the services offered in private hospitals to ensure that no one is deprived. The physical environment and amenities are not awful, but each hospital should do more to improve the quality of the facilities and atmosphere. The most important thing is that these institutions should charge a reasonable cost so that everyone, not just the rich, may benefit from their services. This will improve the health of people in Rangpur City, Bangladesh, as well as the profitability of private healthcare facilities. Thus, in order to build a healthy Rangpur city, a focus on improving private medical hospital service quality is a pressing requirement.

\section{ACKNOWLEDGEMENT:}

At first, all gratefulness goes to the Almighty Allah for keeping us healthy to complete this research paper. Gratitude goes to all the respondents who gave their valuable time for the survey and all others who directly or indirectly contributed in preparing this study. 


\section{CONFLICTS OF INTEREST:}

The authors declared there are no conflicts of interest to publish the present research study.

\section{REFERENCES:}

1) Abul Kalam, (2020). Patient Satisfaction on health Service Provided through Tairunnessa Memorial Medical College \& Hospital- Gazipur. Journal of Nursing and Health Science (IOSRJNHS). 9(4), Ser. IX, pp. 01-08. https://doi.org/10.9790/1959-0904090108

2) Ahmed MS. (2005). Exploring Health Seeking Behaviour of Disadvantage Populations in Rural Bangladesh, International Health Dept. of Public Health Science, Karolinska Institute, Stockholm, Sweden.

https://openarchive.ki.se/xmlui/handle/10616/39135

3) Ahmed et al. (2017). Service quality, patient satisfaction and loyalty in the Bangladesh healthcare sector. International journal of health care quality assurance, 30(5), pp. 477-488. https://doi.org/10.1108/IJHCQA-01-2017-0004

4) Andaleeb et al. (2007). 'Patient satisfaction and quality of hospital services in Bangladesh, Health Policy and Planning, 22(263).

https://doi.org/10.1093/heapol/czm017

5) Andaleeb, S. S. (2000). Public and private hospitals in Bangladesh: service quality and predicttors of hospital choice. Health policy and planning, 15(1), 95-102.

https://doi.org/10.1093/heapol/15.1.95

6) Begum et al., (2021). Healthcare Cost and Patient Satisfaction: A Comparative Analysis between Public and Private Hospitals in Bangladesh. https://doi.org/10.21203/RS.3.RS-325300/V1

7) Dey T, Salam MA, and Saha T. (2021). Evaluation and analysis of user satisfaction of ridesharing service: an assurance and empathy in Bangladesh perspective, Can. J. Bus. Inf. Stud., 3(2), 22-28.

https://doi.org/10.34104/cjbis.021.022028

8) Elbeck M. (1987). An approach to client satisfaction measurement as attribute of health service quality. Health Care Management Review 12(3), 47-52.

https://doi.org/10.1097/00004010-198701230-00 009

UniversePG I www.universepg.com
9) Gronroos C. (2001). The perceived service quality concept- a mistake? Managing Service Quality. 11: 150-162.

10) Hasan et al. (2012). Measuring Service quality of private medical college hospitals: A case study on Sylhet city. SIU studies 3(II), 57-71.

11) Hussain, M. M., \& Raihan, M. M. H. (2016). Patients' satisfaction with public health care services in Bangladesh: Some critical issues. Malaysian J. of Medical and Biological Research, 3(1), pp.51-62. https://doi.org/10.18034/mjmbr.v3i1.405

12) Irfan et al. (2012) 'Patient satisfaction and service quality of public hospitals in Pakistan', Middle-East J. of Scientific Research, 12(6), pp.870-877.

https://doi.org/10.5829/idosi.mejsr.2012.12.6.2743

13) Jin et al. (2013) 'Identifying key factors of patient satisfaction based on SERVQUAL and DEMATEL', Journal of Theoretical and Applied Information Technology, 48(2), pp.973-978. https://researchcor.com/servqual-model/

14) Johnson, W.C. (2013). Outpatient service quality perceptions in private Thai hospitals. International Journal of Business and Social Science, 4(2), pp.56-57.

15) Krowinski and Steiber, (1996). Measuring patient satisfaction. Chicago: American Hospital Publishing.

16) Kulkarni et al. (2011). Study of Satisfaction of Patients Admitted in a Tertiary Care Hospital in Nagpur. National Journal of Community Medicine. 2(1), 37-39.

http://njcmindia.org/uploads/2-1_37-39.pdf

17) Kwortnik, RJ (2005): 'Preparing for Disaster Recommendations Based on the Blackout of 2003". Cornell Hotel and Restaurant Administration Quarterly, 46(1), 47-51.

https://doi.org/10.1177/0010880404272016

18) Mahejabinet al. (2016). Patients Satisfaction with Services Obtained from a Health Care Centre in Rural Bangladesh. Delta Medical College J., 4(2), 77-82.

https://doi.org/10.3329/dmcj.v4i2.29377

19) Manimaran et al. (2010). A study of patients' expectations and satisfaction in Dindigul Hospitals. Asian Journal of Management Research, 1(1), pp.31-43. 
20) Mashhadiabdol et al. (2014). Analysis of the gap between customers' perceptions and employees' expectations of service quality based on fuzzy SERVQUAL logic (case study: Mofid children's hospital in Tehran, Iran). Int. J. of Services and Operations Management, 17(2), pp.119-141.

21) Mezgebe A. (2020). Effect of electronic marketing on customer satisfaction: the case of four star hotels in Addis Ababa, Int. J. Manag. Account. 2(4), 74-95.

https://doi.org/10.34104/ijma.020.074095

22) Parasuraman et al. (1988). SERVQUAL: a multiitem scale for measuring consumer perceptions of the service quality. Journal of Retailing. 64(1), pp. 12-40.

23) Parasuraman et al. (1991). Refinement and reassessment of the SERVQUAL scale. Journal of Retailing. 67, pp. 420-450.

https://www.researchgate.net/profile/ValarieZeithaml-2/publication/247373898

24) Parasuraman et al. (1985). A conceptual model of service quality and its implication. Journal of Marketing, 49, fall, pp. 41-50.

25) Parasuraman et al. (1986). SERVQUAL: a multiple-item scale for measuring customer perceptions of service quality. Marketing Science Institute, Cambridge, MA. Report No. 86-108.

26) Patterson, P.G. and Spreng, R.A., (1997). Modeling the Relationship between Perceived Value, Satisfaction and Repurchase Intentions in a Business-to-business, Services Context: An Empirical Examination. International Journal of Service Industry Management, 8(5), 414-434. https://doi.org/10.1108/09564239710189835

27) Rahman, M.R. and Kutubi, S.S. (2013). Assessment of service quality dimensions in healthcare industry - a study on patient's satisfaction with Bangladeshi private hospitals. International J. of Business and Management Invention, 2(4), pp. 59-67.

https://docplayer.net/13486547-Assessment-of-se rvice-quality-dimensions-in-healthcare-industry-astudy-on-patient-s-satisfaction-with-bangladeshiprivate-hospitals.html

28) Ramez, W. S. (2012). Patient's perception of health care quality, satisfaction and behavioral intention: an empirical study in Bahrain. Inter- national Journal of Business and Social Science, 3(18), pp.131-141.

https://doi.org/10.1177/0972063418822583

29) Richardo et al. (2004). Comparative advantage of public and private providers in health care service in terms of cost, pricing, quality and accessibility, Dhaka: Health Economics Unit, Ministry of Health and Family Welfare, GOB.

30) Rust R., and Zahorik A. (1996). Customer Satisfaction, Customer Retention and Market Share. Journal of Retailin. 69, 193-215. https://doi.org/10.1016/0022-4359(93)90003-2

31) Shamsu Uddin, (2012). Private Hospitals in Rangpur City, Bangladesh: An Issue of Service Marketing. Asian Business Review, 1(1), pp.5-16.

32) Sohail, S.M. (2003). Service quality in hospitals: more favorable than you might think', Managing Service Quality. 13(3), pp.197-206.

33) Solayappan et al. (2011). Quality measurement for hospital services. International Conference on Information and Financial Engineering IPEDR, 12, pp. 1-5.

http://www.ipedr.com/vol12/44-C111.pdf

34) Sower et al. (2001). The dimensions of service quality for hospitals: development and use KQCAH scale. Health Care Management Review, 26(2), pp.47-59.

https://doi.org/\%2010.1097/00004010-200104000$\underline{00005}$

35) Steiber SR. (1989). Preventing pitfalls in patient surveys. Health Care Strategic Management (May): 13-16.

https://europepmc.org/article/med/10293191

36) Uddin et al. (2016). Patient Satisfaction with Doctors' care In Bangladesh: A Case of Government Hospital. International Journal of Social, Political and Economic Research, 3(1), 30-46. https://doi.org/10.46291/IJOSPERvol3iss1pp30-46

37) Verma A, and Sarma RK. (2000). Evaluation of the Exit Proformas in Use at Special Wards of Public Sector Tertiary Care Center. Journal of Academy of Hospital Administration. 12(1), 1-6. http://dx.doi.org/10.18203/2394-6040.ijcmph20172 152

38) World Bank, (1987). Bangladesh: Promoting Higher Growth and Human Development. A World Bank Country Study. Washington, DC. 
39) World Health Organization, (2003). What are the best strategies for ensuring quality in hospitals? Europe Health Evidence Network.

https://www.euro.who.int/_data/assets/pdf_file/00 06/74706/E82995.pdf

40) Zamil et al. (2012). The impact of health service quality on patients' satisfaction over private and public hospitals in Jordan: a comparative study. International J. of Marketing Studies, 4(1), pp. 23-137. http://dx.doi.org/10.5539/ijms.v4n1p123

41) Zeithaml, V.A., and Mary J Bitner (2003). Service Marketing Integrating Customer Focus acros the Firm, $4^{\text {th }}$ edition, Tata McGraw Hill publiccation, 59(83), 112.476.

42) Zubayer, M. (2017). Measuring Healthcare Services Quality in The Private Hospitals of Dhaka city, Bangladesh: An empirical study. British Journal of Marketing Studies, 5(1), 6-26. https://www.eajournals.org/wp-content/uploads/M easuring-Healthcare-Services-Quality-in-the-Priva te-Hospitals-of-Dhaka-City-Bangladesh-An-Empi rical-Study.pdf

Citation: Aktar MS. (2021). Determinates service quality and its effect on patients' satisfaction of private medical college hospitals, Rangpur, Bangladesh, Int. J. Manag. Account. 3(4), 91-105. https://doi.org/10.34104/ijma.021.0910105@) 